\title{
HUBUNGAN ANKLE BRACHIAL INDEX DENGAN KEPARAHAN ULKUS PADA PENDERITA KAKI DIABETIK
}

\author{
Amelia L. Kristiani \\ Richard M. Sumangkut \\ Hilman P. Limpeleh
}

\author{
Bagian Bedah Sub Bagian Bedah Vaskuler RSUP Prof. Dr. R. D. Kandou/ \\ Fakultas Kedokteran Universitas Sam Ratulangi Manado \\ Email: louisa_pb@yahoo.com
}

\begin{abstract}
This study aimed to determine the relationship between ankle brachial index (ABI) and the severity of ulcer using Wagner classification among patients with diabetic foot in Prof. Dr. R. D. Kandou Hospital Manado. This was an observational study with a cross-sectional design conducted at the Department of Surgery and Department of Internal Medicine of Prof. Dr. R.D. Kandou Manado Hospital from January to June 2015. The results showed that there were 38 patients with diabetic foot ulcers. The highest proportion was the group of patients with Wagner grade 4 (10 patients - 26.3\%), followed by grade 1 (9 patients - 23.7\%), grade 2 and 3 (each of 8 patients - 21.05\%), and grade 5 (3 patients - 7.9\%). There were 22 patients (57.9\%) with normal ABI values, followed by moderate ischemia in 8 patients (21.1\%), mild ischemia in 7 patients (18.4\%), and only 1 patient (2.6\%) with severe vascular obstruction. The Spearman test showed a $\mathrm{P}$ value of 0.008 which meant that there was a significant correlation between $\mathrm{ABI}$ and the severity of ulcer. The lower the ABI value, the more severe the ulcer of diabetic foot cases Conclusion: ABI value had a significant relationship with the severity of ulcers of diabetic foot patients.
\end{abstract}

Keywords: ABI, diabetic foot

\begin{abstract}
Abstrak: Penelitian ini bertujuan untuk mengetahui hubungan Ankle Brachial Index (ABI) dengan derajat keparahan ulkus pada penderita dengan kaki diabetik yang dirawat di RSUP Prof. Dr. R. D. Kandou Manado. Penelitian berupa studi observasional dengan desain potong lintang yang dilakukan di Bagian Bedah dan Bagian Penyakit Dalam RSUP Prof. Dr. R. D. Kandou Manado selama periode Januari sampai Juni 2015. Hasil penelitian mendapatkan 38 penderita kaki diabetik dengan proporsi terbanyak yaitu penderita dengan ulkus Wagner grade 4 sebanyak 10 pasien (26,3\%), diikuti grade 1 sebanyak 9 pasien (23,7\%), grade 2 dan 3 masing-masing sebanyak 8 pasien (21,05\%), dan terakhir ulkus Wagner grade 5 sebanyak 3 pasien (7,9\%). Nilai ABI normal didapatkan paling banyak yaitu pada 22 pasien (57,9\%), diikuti oleh obstruksi vaskular sedang sebanyak 8 pasien $(21,1 \%)$ dan iskemi ringan sebanyak 7 pasien (18,4\%), dan hanya 1 pasien (2,6\%) dengan obstruksi vaskular berat. Hubungan ABI dan keparahan ulkus diuji dengan analisis koefisien koreksi Spearman dan mendapatkan nilai $P=0,008$ yang menunjukkan makin rendah nilai ABI maka nilai keparahan ulkus semakin besar. Simpulan: Nilai ABI memiliki hubungan bermakna dengan keparahan ulkus penderita kaki diabetik.
\end{abstract}

Kata kunci: ABI, kaki diabetik

Kaki diabetik adalah infeksi, ulserasi, dan atau destruksi jaringan ikat dalam yang berhubungan dengan neuropati dan penyakit vaskuler perifer pada tungkai bawah. ${ }^{1} \quad$ Hiperglikemia pada diabetes melitus (DM) yang tidak dikelola dengan 
baik akan menimbulkan berbagai komplikasi kronis yaitu neuropati perifer dan angiopati. $^{2}$ Dengan adanya angiopati perifer dan neuropati, trauma ringan dapat menimbulkan ulkus pada penderita DM. Ulkus tersebut mudah terinfeksi karena respons kekebalan tubuh pada penderita DM biasanya menurun. Ketidaktahuan pasien dan keluarga membuat ulkus bertambah parah dan menjadi gangren yang terinfeksi. ${ }^{3,4}$

Pada tahun 2013, proporsi penduduk Indonesia yang berusia $\geq 15$ tahun dengan DM 6,9\%. Prevalensi DM yang terdiagnosis dokter tertinggi terdapat di DI Yogyakarta (2,6\%), DKI Jakarta (2,5\%), Sulawesi Utara (2,4\%), dan Kalimantan Timur (2,3\%). Prevalensi DM yang terdiagnosis dokter atau berdasarkan gejala, tertinggi terdapat di Sulawesi Tengah (3,7\%), Sulawesi Utara (3,6\%), Sulawesi Selatan (3,4\%), dan Nusa Tenggara Timur $(3,3 \%){ }^{5}$

Penyakit pembuluh arteri perifer (PPAP) pada penyandang DM kejadiannya 4 kali lebih sering dibandingkan pasien non-DM. Selain DM, faktor risiko yang memudahkan terjadinya penyakit arteri perifer oklusif ialah merokok, hipertensi, dan hiperlipidemia. Arteri perifer yang sering terganggu ialah arteri tibialis dan arteri peroneal, terutama daerah antara lutut dan sendi kaki. Iskemi menyebabkan terganggunya distribusi oksigen dan nutrisi sehingga ulkus sulit menyembuh.,

Secara klinis adanya oklusi dapat dinilai melalui perabaan nadi arteri poplitea, tibialis, dan dorsalis pedis. Untuk menentukan patensi vaskuler dapat digunakan beberapa pemeriksaan non invasif seperti: ankle brachial index (ABI), transcutaneous oxygen tension $\left(\mathrm{TcP}_{2}\right)$, USG color Doppler, atau menggunakan pemeriksaan invasif seperti: Digital Subtraction Angiography (DSA), Magnetic Resonance Angiography (MRA), atau Computed Tomography Angiography (CTA) ${ }^{8,9}$

Penelitian yang dilakukan oleh Ikem et al. ${ }^{10}$ mendapatkan angka kejadian PPAP yang ditentukan dengan tidak terabanya $>2$ pulsasi baik dengan hanya menggunakan palpasi maupun dengan menggunakan ABI yaitu sebesar 25,7\% dan 55,4\%. Pada penelitian ini dinyatakan bahwa penilaian dengan menggunakan palpasi bersifat subyektif sedangkan penggunaan Doppler bersifat kuantitatif dan lebih dapat dipercaya.

Pada penelitian yang dilakukan oleh Faglia et al. disimpulkan bahwa pengukuran ABI dianggap sebagai metode noninvasif yang paling akurat dalam mengevaluasi PPAP dan direkomendasikan pada penderita DM usia $>50$ tahun. ${ }^{11,12}$

Hasil penelitian $\mathrm{Xu}$ et al. ${ }^{13}$ mendapatkan adanya level spesifisitas yang tinggi 83,3-99,0\% dan ketepatan 72,1-89,2\% pada ABI $\leq 0,90$ dalam mendeteksi stenosis pembuluh darah $\geq 50 \%$. Penelitian ini menyimpulkan bahwa nilai $\mathrm{ABI} \leq 0,9$ dapat menjadi alat pemeriksaan yang sederhana dan berguna untuk mengidentifikasi PPAP dengan stenosis berat dan dapat dipakai sebagai pengganti untuk pemeriksaan noninvasif lainnya dalam penggunaan klinik. ${ }^{13}$

Masalah pada kaki diabetik misalnya ulserasi, infeksi, dan gangren, merupakan penyebab umum perawatan di rumah sakit bagi para penyandang DM. Perawatan rutin ulkus, pengobatan infeksi, amputasi, dan perawatan di rumah sakit membutuhkan biaya yang sangat besar tiap tahun dan menjadi beban yang sangat besar dalam sistem pemeliharaan kesehatan.

Saat ini RSUP Prof. Dr. R. D. Kandou Manado belum memiliki data mengenai ABI pada penderita kaki diabetik dengan ulkus oleh karena pemeriksaan ini belum menjadi pemeriksaan rutin pada penyandang DM. Data ABI sangat penting untuk menentukan prognosis kaki diabetik.

\section{METODE PENELITIAN}

Penelitian ini menggunakan metode observasional dengan desain potong lintang yang dilakukan di Bagian Bedah dan Bagian Penyakit Dalam RSUP Prof. Dr. R. D. Kandou Manado pada bulan Januari 2015 sampai Juni 2015.

Subyek penelitian ialah semua penyandang DM dengan komplikasi kaki 
diabetik yang menjalani pengobatan di RSUP Prof. Dr. R. D. Kandou Manado. Kriteria inklusi yaitu: penderita kaki diabetik dengan komplikasi ulkus (klasifikasi Wagner) di Bagian Bedah dan Bagian Penyakit Dalam RSUP Prof. Dr. R. D. Kandou Manado yang bersedia untuk diikutkan dalam penelitian ini dan memenuhi aturan-aturan penelitian. Yang termasuk kriteria eksklusi yaitu: penderita dengan keganasan, koagulopati, atau penyakit pembuluh arteri perifer yang lain. Derajat keparahan ulkus dievaluasi sekaligus dilakukan pengukuran ABI menggunakan hand held Doppler. Nilai ABI diperoleh dengan mengukur tekanan sistolik pada ankle kanan dan kiri lalu tekanan sistolik pada brachial kanan dan kiri, kemudian tekanan sistolik tertinggi ankle dibagi dengan tekanan sistolik tertinggi brachial. Analisis data hubungan ABI dengan keparahan ulkus diuji dengan analisis koefisien koreksi Spearman.

\section{HASIL PENELITIAN DAN BAHASAN}

Kaki diabetik merupakan salah satu komplikasi tersering pada penderita DM yang sangat ditakuti karena dapat menyebabkan cacat bahkan kematian; juga menjadi salah satu penyebab utama terjadinya amputasi nontraumatik pada ekstremitas inferior. Hal ini menjadi beban ekonomi tidak hanya untuk penderita namun juga bagi institusi kesehatan. Alavi et al. melakukan penelitian tentang Audible handheld Doppler Ultrasoud dan menyimpulkan bahwa Audible handheld Doppler Ultrasoud terbukti sebagai alat tes yang sederhana, cepat, handal, dan tidak mahal untuk menyingkirkan PPAP pada pasienpasien DM maupun tanpa DM. ${ }^{14}$

Penelitian oleh Moosa et al. ${ }^{15}$ mendapatkan prevalensi PPAP meningkat sesuai dengan usia dimana terdapat $4,2 \%$ pada usia $<60$ tahun, $8,1 \%$ pada usia $60-70$ tahun, serta $11 \%$ pada pasien usia $>70$ tahun. PPAP didapatkan pada penyandang DM sebanyak 5,4\% melalui pemeriksaan ABI, dimana merokok merupakan faktor yang berhubungan dengan ABI yang rendah. Potier et al. ${ }^{16}$ melaporkan bahwa ABI yang rendah berhubungan dengan mortali-tas yang masing-masing sama besarnya baik pada penderita dengan DM maupun yang tanpa DM. Penelitian oleh Bishara et $\mathrm{al}^{17}$ yang menggunakan Ankle Peak Systolic Velocity (APSV) untuk memrediksi ulkus diabetik yang tidak sembuh mendapatkan hasil bahwa APSV pada kaki dengan ulkus yang sembuh atau dalam penyembuhan lebih tinggi dibandingkan pada kaki dengan ulkus yang tidak menyembuh. Terdapat perbedaan bermakna pada APSV sebelum dan sesudah dilakukan revaskularisasi.

Dalam periode Januari 2015 s/d akhir Juni 2015 didapatkan sebanyak 38 kasus kaki diabetik di Bagian Bedah dan Bagian Ilmu Penyakit Dalam RSUP Prof. Dr. R.D. Kandou Manado (Tabel 1). Dari total 38 pasien terdapat 21 perempuan $(55,3 \%)$ dan 17 laki-laki (44,7\%) dengan rasio perempuan : laki-laki 1,2:1. Penelitian lain oleh Sei et al. ${ }^{18}$ di Amerika mendapatkan rasio penyandang DM perempuan : lakilaki 2:1, sedangkan penelitian oleh Choi et al. ${ }^{19}$ di Korea Selatan mendapatkan rasio penyandang DM laki-laki : perempuan dengan perbandingan 2:1. Hal-hal ini memperlihatkan bahwa perbedaan jenis kelamin pada beberapa penelitian tidak sama walaupun acuan teori menyatakan bahwa jenis kelamin laki-laki mempunyai faktor risiko tinggi terhadap kaki diabetik. ${ }^{8}$

Penderita terbanyak berada pada usia $>50$ tahun yaitu sebanyak 29 orang (76,3\%) dengan usia rerata 55,08 tahun. Penelitian di Amerika Serikat melaporkan bahwa persentase kaki diabetik tertinggi pada usia 45-64 tahun. ${ }^{14}$

Lanjut usia biasanya memiliki keterbatasan gerak, penglihatan yang buruk, dan masalah penyakit yang lain. Lanjut usia berkaitan dengan terjadinya kaki diabetik sangat tinggi karena fungsi tubuh secara fisiologik menurun. Rerata usia pada penelitian Moosa et al. ${ }^{15}$ di Jordania ialah 60,5 tahun sedangkan Choi et al. ${ }^{19}$ di Korea Selatan mendapatkan rerata usia 63,9 tahun. 
Tabel 1. Deskripsi karakteristik subyek penelitian

\begin{tabular}{|c|c|c|c|}
\hline \multicolumn{2}{|l|}{ Karakteristik } & $\mathrm{n}$ & (\%) \\
\hline \multirow[t]{2}{*}{ Usia (tahun) } & $<50$ & 9 & $(23,7)$ \\
\hline & $\geq 50$ & 29 & $(76,3)$ \\
\hline \multirow[t]{2}{*}{ Jenis Kelamin } & Laki-laki & 17 & $(44,7)$ \\
\hline & Perempuan & 21 & $(55,3)$ \\
\hline \multirow[t]{3}{*}{ IMT } & Normal & 20 & $(52,7)$ \\
\hline & Overweight & 10 & $(26,3)$ \\
\hline & Obese & 8 & $(21,0)$ \\
\hline \multirow[t]{2}{*}{ HbA1c (\%) } & $<7$ & 6 & $(15,8)$ \\
\hline & $\geq 7$ & 32 & $(84,2)$ \\
\hline \multirow[t]{2}{*}{ Hipertensi } & Tidak & 17 & $(44,8)$ \\
\hline & Ya & 21 & $(55,3)$ \\
\hline \multirow[t]{2}{*}{ Hiperkolesterolemia (mg/dL) } & Tidak & 13 & $(34,2)$ \\
\hline & Ya & 25 & $(65,8)$ \\
\hline \multirow[t]{3}{*}{ Lama DM (tahun) } & $<5$ & 7 & $(18,4)$ \\
\hline & $5-10$ & 14 & $(36,8)$ \\
\hline & $>10$ & 17 & $(44,8)$ \\
\hline
\end{tabular}

Hal ini juga sesuai dengan penelitian yang dilakukan oleh Brito-Zurita et al. ${ }^{20}$ dan Arnadi et al. ${ }^{14}$ dimana terdapat hubungan bermakna antara usia $\geq 55$ tahun dengan peningkatan kejadian PPAP pada DM tipe 2 dengan nilai kemaknaan $P=$ 0,548 dan $P=0,037$.

Terdapat 20 pasien (52,7\%) dengan berat badan normal, 10 pasien $(26,3 \%)$ dengan berat badan overweight, dan 8 pasien (21,0\%) dengan obesitas. DM berpengaruh pada progresifitas terbentuknya lesi aterosklerosis pada ekstremitas inferior sehingga bermanifestasi sebagai kalsifikasi arteri ekstremitas inferior. Hal tersebut di atas sesuai dengan penelitian ini dimana nilai rerata $\mathrm{HbA} 1 \mathrm{c}$ penderita dengan ulkus grade 5 (13,3\%) lebih besar dibandingkan dengan nilai rerata HbA1c penderita dengan ulkus grade 1 (7,4\%) dimana rerata HbA1c keseluruhan penderita ialah $8,7 \%$ yaitu termasuk klasifikasi DM tidak terkontrol.

Dari penelitian ini didapatkan penderita kaki diabetik dengan komplikasi ulkus disertai hipertensi sebanyak 21 orang $(55,3 \%)$ dan nilai rerata kolesterol total sebesar 209,5 mg/dL sebanyak 25 pasien (65,8\%). Hipertensi dan hiperkolesterolemia memiliki korelasi yang besar dengan penurunan aliran darah ke perifer pada penyandang DM. Pada penelitian ini didapatkan lebih banyak penderita dengan hipertensi dan dengan hiperkolesterolemia $>200 \mathrm{mg} / \mathrm{dL}$. Faktor risiko hipertensi, hiperkolesterolemia, dan DM yang tidak terkontrol masing-masing berdampak lebih banyak penderita kaki diabetik yang disertai ulkus. $^{20}$

Penderita dengan penyakit DM $>10$ tahun sebanyak 17 pasien $(44,8 \%)$, antara 5-10 tahun sebanyak 14 pasien (36,8\%), dan $<5$ tahun sebanyak 7 pasien $(18,4 \%)$. Rerata lama menderita DM dari keseluruhan penderita ialah 10,13 tahun. Hal ini sesuai dengan penelitian oleh Arnadi et al. ${ }^{14}$ bahwa kebanyakan kasus DM akan mengalami komplikasi PPAP setelah perjalanan penyakitnya $>5$ tahun $(P$ $=0,044)$. Jika kadar glukosa darah tinggi, maka akan timbul komplikasi yang berhubungan dengan saraf dan aliran darah ke kaki. Komplikasi pada saraf dan aliran darah ke kaki ini yang menyebabkan terjadinya neuropati dan PPAP.

Proporsi penderita kaki diabetik berdasarkan klasifikasi Wagner yang terbanyak ialah yang dengan ulkus derajat 4 (10 pasien - 26,3\%), diikuti grade 1 (9 pasien - 23,7\%), grade 2 dan 3 masingmasing sebanyak 8 pasien $(21,05 \%)$, dan terakhir grade 5 (3 pasien - 7,9\%). Hasil 
yang didapatkan hampir serupa dengan penelitian Akhter et al. ${ }^{21}$ di India dimana dari jumlah 55 sampel didapatkan yang terbanyak ialah penderita dengan ulkus derajat 2 (19 pasien - 34,5\%), diikuti grade 3 (13 pasien - 23,6\%), grade 4 dan 1 masing-masing sebanyak 11 dan 9 pasien (20,0\% dan 16,4\%), dan terakhir grade 5 (3 pasien - 5,4\%). Pada penelitian yang dilakukan Sun et al. ${ }^{22}$ di Taiwan, penderita kaki diabetik derajat 4 lebih banyak mengalami amputasi mayor dibandingkan dengan derajat yang lebih rendah.
Nilai ABI normal didapatkan paling banyak yaitu pada 22 pasien (57,9\%), diikuti oleh obstruksi vaskular sedang (8 pasien - 21,1\%), iskemi ringan (7 pasien 18,4\%), dan hanya 1 pasien (2,6\%) dengan obstruksi vaskular berat. Pada penelitian ini nilai ABI normal banyak didapatkan pada ulkus derajat 1 dan 3 (77,8\% dan 75\%), sedangkan obstruksi vaskular berat hanya didapatkan pada ulkus derajat 5. Hubungan ABI dengan keparahan ulkus menurut klasifikasi Wagner terdapat pada Tabel 2.

Tabel 2. Hubungan ABI dengan keparahan ulkus menurut klasifikasi Wagner

\begin{tabular}{|c|c|c|c|c|c|c|}
\hline \multirow[b]{2}{*}{ ABI } & \multicolumn{5}{|c|}{ Klasifikasi Wagner } & \multirow[b]{2}{*}{$\begin{array}{c}\text { Total } n=38 \\
(100 \%)\end{array}$} \\
\hline & $\begin{array}{c}\text { Grade } 1 \\
n=9 \\
(100 \%)\end{array}$ & $\begin{array}{c}\text { Grade } 2 \\
n=8 \\
(100 \%)\end{array}$ & $\begin{array}{c}\text { Grade } 3 \\
n=8 \\
(100 \%)\end{array}$ & $\begin{array}{c}\text { Grade } 4 \\
n=10 \\
(100 \%)\end{array}$ & $\begin{array}{c}\text { Grade } 5 \\
n=3 \\
(100 \%)\end{array}$ & \\
\hline$>0,90$ & $7(77,8)$ & $4(50)$ & $6(75)$ & $5(50)$ & 0 & $22(57,9)$ \\
\hline $0,71-0,90$ & $2(22,2)$ & $2(25)$ & 0 & $2(20)$ & $1(33,3)$ & $7(18,4)$ \\
\hline $0,41-0,70$ & 0 & $2(25)$ & $2(25)$ & $3(30)$ & $1(33,3)$ & $8(21,1)$ \\
\hline$\leq 0,40$ & 0 & 0 & 0 & 0 & $1(33,3)$ & $1(2,6)$ \\
\hline
\end{tabular}

Pengujian hubungan ABI dan keparahan ulkus dianalisis dengan koefisien korelasi Spearman. Hasil yang diperoleh ialah $\mathrm{r}_{\mathrm{s}}=-0,388$ dengan $P=0,008$ yang menyatakan terdapat hubungan bermakna antara ABI dengan keparahan ulkus. Makin rendah ABI maka makin parah ulkus. Grafik hubungan ABI dan keparahan ulkus dapat dilihat pada Gambar 1.

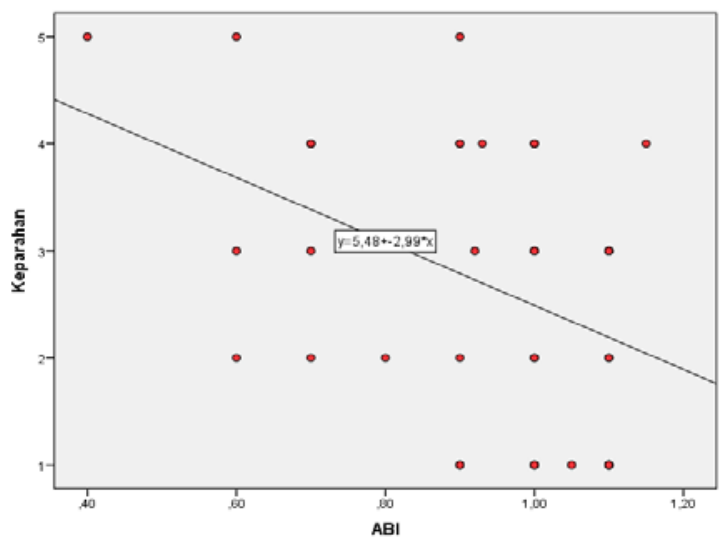

Gambar 1. Scatter plot hubungan ABI dengan keparahan ulkus
Ulkus diabetik terjadi melalui dua mekanisme yaitu angiopati dan neuropati. Ulkus dapat terjadi sebagai hasil dari salah satu mekanisme atau akibat kedua mekanisme tersebut. Ulkus diabetik akibat neuropati biasanya memiliki ABI yang normal namun bila ulkus neuropati disertai adanya angiopati maka derajat ulkus dapat bertambah berat sesuai dengan beratnya iskemia jaringan yang pada penelitian ini diukur dengan menggunakan ABI.

Hasil penelitian ini menyatakan terdapat hubungan bermakna antara ABI dengan keparahan ulkus $(P=0,008)$. Makin rendah nilai ABI maka nilai keparahan ulkus semakin besar. Secara statistik derajat iskemia perifer dapat memengaruhi terjadinya kaki diabetik sejalan dengan keparahan ulkus. Perhatian khusus harus diberikan pada kaki penderita DM untuk mencegah terjadinya luka dengan mengontrol faktor-faktor risiko, mengidentifikasi kaki berisiko, dan edukasi pada penderita DM. Pencegahan terhadap 
amputasi ekstremitas nontraumatik akibat DM harus menjadi prioritas utama yaitu dengan melakukan pemeriksaan sirkulasi ekstremitas inferior terutama pada penderita DM yang sudah lama dengan atau tanpa faktor risiko kardiovaskuler.

\section{SIMPULAN}

Dari hasil penelitian yang dilakukan di Bagian Bedah dan Bagian Penyakit Dalam RSUP Prof. Dr. R. D. Kandou Manado pada bulan Januari 2015 sampai Juni 2015 terhadap penderita DM dengan komplikasi kaki diabetik dapat disimpulkan bahwa terdapat hubungan bermakna antara ABI dan keparahan ulkus kaki diabetik. Makin rendah nilai $\mathrm{ABI}$ maka nilai keparahan ulkus semakin tinggi.

\section{SARAN}

Perlu dilakukan pengukuran ABI dengan menggunakan Doppler sebagai sebagai metode noninvasif yang akurat dan mudah dalam monitoring kaki pada penyandang DM lama dengan atau tanpa faktor risiko kardiovaskuler.

Pada setiap penyandang DM perlu diinformasikan mengenai komplikasi iskemi perifer dan neuropati iskemik pada kaki diabetik untuk mencegah komplikasi yang lebih lanjut.

Perlu dilakukan penelitian lebih lanjut dengan menggunakan metode penelitian yang lebih baik (case control) dan proporsi jumlah sampel yang seimbang untuk setiap derajat ulkus.

\section{DAFTAR PUSTAKA}

1. Powers AC. Diabetes mellitus. In: Harrison's Principles of Internal Medicine (16th ed.). New York: McGraw-Hill, 2005; p. 2152-79.

2. Boulton AJ, Kirsner S, Vileykite L. Neuropathic diabetic foot ulcers. N Engl J Med. 2004;351:48-55.

3. PERKENI. Konsensus Pengelolaan dan Pencegahan Diabetes Mellitus Tipe 2 di Indonesia. Jakarta, 2011.

4. ADA. Standards of Medical Care in Diabetes. USA, 2011.
5. Kemenkes. Riset Kesehatan Dasar: Riskesdas 2013. Jakarta: Badan Penelitian dan Pengembangan Kesehatan Kementrian Kesehatan RI, 2013.

6. Singh N, Armstrong DG, Lipsky BA. Preventing foot ulcers in patients with diabetes. JAMA 2005;293:217-21.

7. Waspadji S. Pengelolaan kaki diabetes sebagai suatu model pengelolaan holistik, terpadu dan komprehensif di bidang penyakit dalam. Pidato pada acara pengukuhan sebagai guru tetap dalam Ilmu Penyakit Dalam. Jakarta, Maret 2004.

8. Frykberg RG, Zgonis T, Armstrong DG, Driver VR, Giurini JM, Kravitz SR, et al. Diabetic foot disorders: A clinical practice guideline. Journal of Foot and Ankle Surgery. 2006:45(5) Suppl:2-4.

9. Waspadji S. Komplikasi kronik diabetes: mekanisme terjadinya, diagnosis dan strategi pengelolaan. In: Sudoyo AW, Setyohadi B, Alwi I, Simadibrata M, Setiati S, editors. Ilmu Penyakit Dalam Jilid III (4th ed.). Jakarta: Penerbit FK UI, 2006.

10. Ikem R, Ikem I, Adebayo O, Soyoye D. An Assessment of peripheral vascular disease in patients with diabetic foot ulcer. The International Journal of Clinical Foot Science. 2010;20(4):114-7.

11. Faglia E. Characterisristics of peripheral arterial disease and its relevance to diabetic population. International Journal of Lower Extremity Wounds. 2011;10(3):152-66.

12. AHA Scientific Statement. Measurement and interpretation of the Ankle-Brachial Index. A scientific statement from the American Heart Association, 2012.

13. Xu D, Li J, Zou L, Xu Y, Hu D, Pagoto SL, Ma Y. Sensitivity and specificity of the ankle-brachial index to diagnose peripheral artery disease: a structured review. Vascular Medicine. 2010;15(5):361-9.

14. Arnadi, Subekti I, Waspadji S, Surjadipraja RM, Muthalib A. The prevalence rate of peripheral arterial disease in type 2 diabetes mellitus and associated risk factors. Acta Medica Indonesia. 2003;35:2-8.

15. Moosa SR, Bakri FG, Khammash MR, Jaddou HY, Shatnawi NJ, Ajlouni KM. Peripheral arterial disease in 
diabetic Jordanian patients and the agreement between ankle brachial index and toe brachial index. The British Journal of Diabetes \& Vascular Disease. 2013;13(1):37-47.

16. Potier L, Rousse R, Labreuche J, Marre M, Cacoub P, Röther $J$, et al. Interaction between diabetes and a high ankle-brachial index on mortality risk. European Journal of Preventive Cardiology. 2015;22(5):615-21.

17. Bishara RA, Taha W, Akladious I, Allam MA. Ankle peak systolic velocity: New parameter to predict nonhealing in diabetic foot lesions. Vascular. 2009;17(5):264-8.

18. Osei D, Brechow A, Slesaczeck T, Münch $D$, Nanning $T$, Paetzold $H$, et al. Improving major amputation rates in the multicomplex diabetic foot patient focus on the severity of peripheral arterial disease. Ther Adv Endo Metab. 2013;4(3):83-94.

19. Choi MS, Jeon SB, Lee JH. Predictive factors for successful limb salvage surgery in diabetic foot patients. BMC Surgery. 2014. 14:113. [cited 2015 Feb 2]. Available from: http://www.biomedcentral.com/14712482/14/113.

20. Brito-Zurita OR, Ortega-López S, Castillo-Sánchez D, Vázquez-Téllez AR, Ornelas-Aguirre JM. Anklebrachial index associated with diabetic foot: Case-control study. Cirugía y Cirujanos. 2013;81(2):122-7.

21. Akhter JM, Khan IA, Shahpurkar VV, Khanam N, Syed ZQ. Evaluation of the diabetic foot according to Wagner's classification in a rural teaching hospital. Br J Diabetes Vasc Dis. 2011;11:74-9.

22. Sun JH, Tsai JS, Huang CH, Lin CH, Yang HM, Chan YS. Risk factors for lower extremity amputation in diabetic foot disease categorized by Wagner classification. Diabetes Research and Clinical Practice. 2012. 358-63. [cited 2014 Apr 2]. Available from: www.elsevier.com/locate/diabres. 